\title{
The safety of aprotinin and lysine-derived antifibrinolytic drugs in cardiac surgery: a meta-analysis
}

\author{
David Henry MBChB, Paul Carless BHSc MMedSc (ClinEpid), Dean Fergusson PhD MHA, \\ Andreas Laupacis MD MSc
}

Published at www.cmaj.ca on Nov. 27, 2008. Revised on Jan. 5, 2009.

\section{ABSTRACT}

Background: Because of recent concerns about the safety of aprotinin, we updated our 2007 Cochrane review that compared the relative benefits and risks of aprotinin and the lysine analogues tranexamic acid and epsilon aminocaproic acid.

Methods: We searched electronic databases, including CENTRAL, MEDLINE, EMBASE, Google and Google Scholar for trials of antifibrinolytic drugs used in adults scheduled for cardiac surgery. Searches were updated to January 2008. By comparing aprotinin and the 2 lysine analogues to control, we derived indirect head-to-head comparisons of aprotinin to the other drugs. We derived direct estimates of risks and benefits by pooling estimates from head-to-head trials of aprotinin and tranexamic acid or epsilon aminocaproic acid.

Results: For indirect estimates, we identified 49 trials involving 182 deaths among 7439 participants. The summary relative risk (RR) for death with aprotinin versus placebo was 0.93 (95\% confidence interval [Cl] 0.69-1.25). In the 19 trials that included tranexamic acid, there were 24 deaths among 1802 participants. The summary RR was 0.55 (95\% Cl 0.24-1.25). From the risk estimates derived for individual drugs, we calculated an indirect summary RR of death with use of aprotinin versus tranexamic acid of 1.69 (95\% Cl $0.70-4.10)$. To calculate direct estimates of death for aprotinin versus tranexamic acid, we identified 13 trials with 107 deaths among 3537 participants. The summary RR was 1.43 (95\% Cl 0.98-2.08). Among the 1840 participants, the calculated estimates of death for aprotinin compared directly to epsilon aminocaproic acid was 1.49 (95\% Cl 0.98-2.28). We found no evidence of an increased risk of myocardial infarction with use of aprotinin compared with the lysine analogues in either direct or indirect analyses. Compared with placebo or no treatment, all 3 drugs were effective in reducing the need for red blood cell transfusion. The RR of transfusion with use of aprotinin was $0.66(95 \% \mathrm{Cl} 0.61-0.72)$. The RR of transfusion was 0.70 (95\% Cl 0.61-0.80) for tranexamic acid, and it was 0.75 (95\% Cl 0.58-0.96) for use of epsilon aminocaproic acid. Aprotinin was also effective in reducing the need for reoperation because of bleeding (RR $0.48,95 \% \mathrm{Cl} 0.34-0.67$ ).

Interpretation: The risk of death tended to be consistently higher with use of aprotinin than with use of lysine analogues. Aprotinin had no clear advantages to offset these harms. Either tranexamic acid or epsilon aminocaproic acid should be recommended to prevent bleeding after cardiac surgery.

Une version française de ce résumé est disponible à l'adresse www.cmaj.ca/cgi/content/full/180/2/183/DC1

CMAJ 2009;180(2)183-93
A ntifibrinolytic drugs, such as the bovine-derived polypeptide aprotinin, have been used to minimize blood loss during cardiac surgery for many years. ${ }^{1}$ Meta-analyses of randomized controlled trials have shown convincing and consistent evidence that the use of aprotinin reduces the need for blood transfusion. Some studies have shown that use of aprotinin reduces the need for reoperation because of continued or recurrent bleeding. ${ }^{2-5}$ The synthetic lysine derivatives tranexamic acid and epsilon aminocaproic acid have become more popular in recent years because of randomized controlled trials reporting a decrease in blood loss compared with placebo and because they are considerably less costly than aprotinin. However, there is uncertainty about whether lysine analogues are as effective as aprotinin in controlling perioperative blood loss and reducing the need for allogeneic red blood cell transfusion. ${ }^{2,6}$

Published meta-analyses of placebo controlled trials of aprotinin have found no increase in mortality or vascular thrombosis (a theoretical adverse effect of antifibrinolytic drugs). ${ }^{2,3,5}$ There have also been no increases in mortality or vascular thrombosis in placebo controlled trials of lysine analogues. ${ }^{2}$ The head-to-head randomized controlled trial comparing aprotinin and lysine analogues had few participants; however, there was no difference in the risk of adverse events between aprotinin and lysine analogues. ${ }^{2,6}$ These findings have been criticized because the trials were small, of poor quality, and neither death nor thrombosis was specified as a trial outcome. ${ }^{7}$ As a consequence, there may have been underreporting of these events leading to false negative results. ${ }^{7}$

Several observational studies have suggested that the risk of death, vascular events and renal failure may be greater with the use of aprotinin than with the use of lysine analogues. ${ }^{8-10}$ These initial studies were criticized for inadequate adjustment for known confounding factors, including the type of surgery and patient acuity. ${ }^{2,11,12}$ However, a recent large observational study with careful propensity score matching found a $32 \%$ relative increase in hospital mortality with the use of aprotinin compared with the use of epsilon aminocaproic acid. ${ }^{9}$

From the School of Medicine and Public Health (Henry, Carless), University of Newcastle, Australia; the Ottawa Health Research Institute (Fergusson), The Ottawa Hospital, Ottawa, Ont.; the Keenan Research Centre, Li Ka Shing Knowledge Institute, St. Michael's Hospital (Laupacis); the Institute for Clinical Evaluative Sciences (Henry, Laupacis); and the Faculty of Medicine (Henry, Laupacis), University of Toronto, Toronto, Ont. 


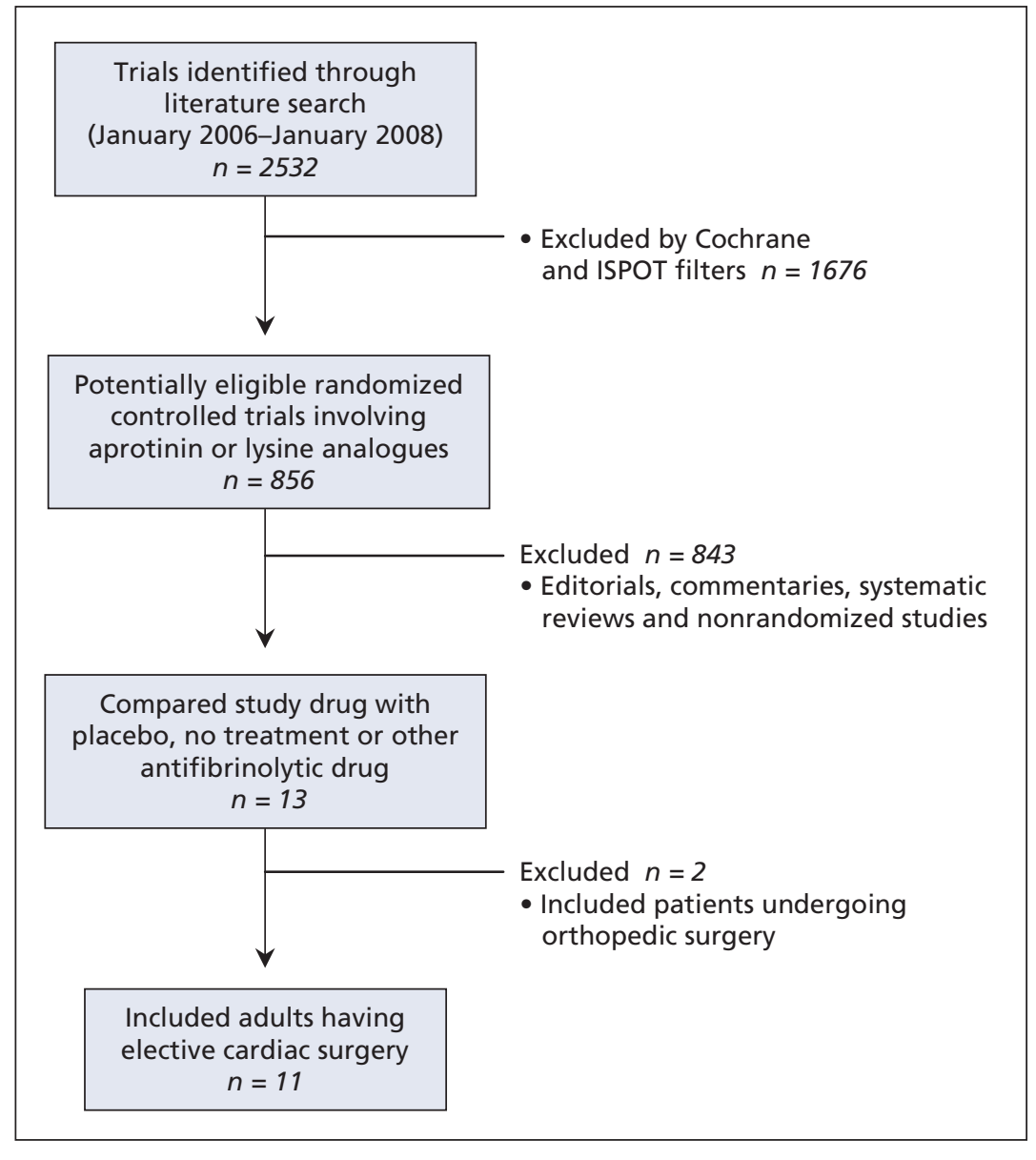

Figure 1: Selection of studies for inclusion in the meta-analysis of the use of aprotinin and lysine analogues in cardiac surgery. Note: ISPOT = International Study of Perioperative Transfusion.

New information has been provided by the Blood Conservation Using Antifibrinolytics in a Randomized Trial (BART) study,${ }^{13}$ which compared the efficacy and safety of aprotinin and lysine analogues in cardiac surgery patients at high risk of perioperative mortality. This large trial was designed to compare the impact of these drugs with respect to clinically important bleeding outcomes. The trial was stopped prematurely (after recruitment of over $80 \%$ of the target sample size) because of an increased number of deaths among the group that received aprotinin. This trial reported a greater than 53\% relative increase in the risk of all-cause mortality and a doubling of the risk of death from cardiac causes among patients who received aprotinin compared to those who received a lysine analogue. ${ }^{13}$

In view of this new information and the apparently conflicting results, we have updated our 2007 Cochrane review ${ }^{2}$ of randomized controlled trials of antifibrinolytic drugs. We have concentrated on trials that examined the use of antifibrinolytic drugs in cardiac surgery, which is a subset of the trials included in the 2007 update of our Cochrane review. ${ }^{2} \mathrm{Al}-$ though the primary outcomes were the need for perioperative allogeneic transfusion and reoperation because of bleeding, we have focused on the safety of antifibrinolytic drugs. We compared the rates of death and vascular occlusion by conducting and updating metaanalyses of direct (head to head) and indirect (common comparator) trials of aprotinin and lysine analogues. ${ }^{2,3}$

\section{Methods}

\section{Search strategy}

The methods used in this review have been described elsewhere and followed the approach recommended by the Cochrane Collaboration., ${ }^{2,14}$ This search was an update of the search performed as part of our 2007 Cochrane review ${ }^{2}$ and covered the period from Jan. 1, 2006, to Jan. 31, 2008. We searched CENTRAL, MEDLINE and EMBASE. We searched the Internet using Google and Google Scholar. The search strategy included the following exploded MEDLINE subject heading terms: aprotinin, tranexamic acid, aminocaproic acids, blood transfusion, hemorrhage, and anesthesia. The text-word terms included in the search strategy included: aprotinin, antilysin, contrical, kallikrein-trypsin, bovine pancreatic trypsin, tranexamic, cyklokapron, pharmacia, t-amcha, amcha, ugurol, transamin, kabi, epsilon aminocaproic acid, aminocaproic, lederle, amicar, transfusion\$, bleed\$, blood loss\$, hemorrhag\$.

The initial electronic searches of MEDLINE were unrestricted to maximize sensitivity. In subsequent MEDLINE searches, 2 filters were used to restrict the searches and improve the specificity. First, we used the International Study of Perioperative Transfusion (ISPOT) filter, which identifies blood transfusion trials. Second, we used a modified version of the Cochrane Collaboration filter, which primarily identifies randomized controlled trials. ${ }^{2}$ These search filters were coupled with the specified medical subject headings and the relevant text-word terms. We also checked the reference lists of relevant reviews, published trials and editorials for potentially relevant trials.

\section{Study selection}

We designed the literature search for the Cochrane review to retrieve trials that examined the use of antifibrinolytic drugs in all types of surgery. ${ }^{2}$ In this review, we included only randomized controlled trials that used antifibrinolytic drugs in adults scheduled for nonurgent cardiac surgery. We considered trials eligible for inclusion if they compared antifibrinolytic drugs with placebo, no treatment or each other.

\section{Statistical analyses}

Two authors (P.C. and D.F.) independently assessed trial quality and extracted data about deaths and vascular events. Differences between authors were resolved by consensus. We assessed trial quality by grading allocation concealment by the method recommended by the Cochrane Collaboration. ${ }^{14}$ 
We used 2 approaches to pool the data. For head-to-head randomized controlled trials that compared aprotinin with either lysine analogue, data were pooled using a randomeffects model. The summary relative risk (RR) and 95\% confidence interval (CI) for aprotinin versus the comparator drug was the principal measure of effect. A similar method was used to derive the summary RR from trials that compared aprotinin and either of the lysine analogues (tranexamic acid or epsilon aminocaproic acid) with a placebo or inactive control. We derived indirect estimates of the summary RR for aprotinin compared with each lysine analogue by dividing the summary values in pairwise comparisons of active treatment versus placebo or no treatment. We used the method of Bucher and colleagues, ${ }^{15}$ which evaluates the differences between treatment and placebo in 2 sets of clinical trials and preserves the randomization of the originally assigned patient groups. ${ }^{15}$ We felt that these additional analyses were justified because the total number of deaths in the placebo or inactive controlled trials was about double the number seen in the direct comparison trials.

There have been concerns that small controlled trials of aprotinin, which are of uncertain quality, may have failed to report uncommon events, such as renal failure, vascular thrombosis and death, which were not specified outcomes. Consequently, we carried out sensitivity analyses that included only trials that recruited more than 100 patients in the active treatment arm. We also examined the effect of allocation concealment on the size of the effect of treatment in the larger trials.

\section{Results}

\section{Study characteristics}

We identified 11 randomized controlled trials ${ }^{13,16-25}$ of the use of antifibrinolytic drugs in cardiac surgery that had not been included in our 2007 Cochrane review. ${ }^{2}$ The retrieval of these trials and aspects of the literature search are described in Figure 1. There was a total of 3054 participants in these 11 trials (Table 1). The details of all other trials included in our analyses are provided in our 2007 Cochrane review. ${ }^{2}$

This updated review summarizes data from 81 placebo or inactive controlled trials of the use of aprotinin in cardiac surgery, including blood transfusions, with a total of 9139 participants. Of these, $49(60 \%)$ trials with 7439 $(81 \%)$ participants reported mortality, and $42(52 \%)$ trials with $5884(64 \%)$ participants reported myocardial infarc-

Table 1: Characteristics of the randomized controlled trials of the use of aprotinin and lysine analogues identified by the updated literature search

\begin{tabular}{|c|c|c|c|c|}
\hline Study & Year & Country & Type of cardiac surgery & Interventions \\
\hline $\begin{array}{l}\text { Rhydderch } \\
\text { et al. }{ }^{23}\end{array}$ & 1993 & Saudi Arabia & $\begin{array}{l}\text { Primary coronary artery bypass graft, valve, } \\
\text { atrial septal defect }\end{array}$ & $\begin{array}{l}\text { Pump prime* aprotinin }(n=25) \\
\text { v. placebo }(n=25)\end{array}$ \\
\hline Feindt et al. ${ }^{19}$ & 1994 & Germany & Primary coronary artery bypass graft & $\begin{array}{l}\text { High-dose aprotinint }(n=10) \\
\text { v. placebo }(n=10)\end{array}$ \\
\hline Gott et al. ${ }^{20}$ & 1998 & United States & $\begin{array}{l}\text { Primary coronary artery bypass graft, valve, } \\
\text { re-operation, ascending aorta }\end{array}$ & $\begin{array}{l}\text { Low-dose aprotinin } \neq(n=109) \\
\text { v. leukocyte filtration }(n=112) \\
\text { v. heparin-bonded circuit }(n=67) \\
\text { v. control }(n=112)\end{array}$ \\
\hline Luo et al. ${ }^{22}$ & 1998 & China & Valve replacement & $\begin{array}{l}\text { Low-dose aprotinin }(n=10) \\
\text { v. control }(n=10)\end{array}$ \\
\hline $\begin{array}{l}\text { Asimakopoulos } \\
\text { et al. }{ }^{16}\end{array}$ & 2000 & $\begin{array}{l}\text { United } \\
\text { Kingdom }\end{array}$ & Primary coronary artery bypass graft & $\begin{array}{l}\text { High-dose aprotinin }(n=8) \\
\text { v. placebo }(n=10)\end{array}$ \\
\hline $\begin{array}{l}\text { Cicekcioglu } \\
\text { et al. }{ }^{17}\end{array}$ & 2006 & Turkey & Primary coronary artery bypass graft & $\begin{array}{l}\text { Low-dose aprotinin }(n=24) \\
\text { v. placebo }(n=20)\end{array}$ \\
\hline Kuitunen et al. ${ }^{21}$ & 2006 & Finland & Primary coronary artery bypass graft and valve & $\begin{array}{l}\text { Tranexamic acid§ }(n=15) \\
\text { v. placebo }(n=15)\end{array}$ \\
\hline Murphy et al. ${ }^{24}$ & 2006 & Italy & Primary off-pump coronary artery bypass graft & $\begin{array}{l}\text { Tranexamic acid§ }(n=50) \\
\text { v. placebo }(n=50)\end{array}$ \\
\hline Wei et al. ${ }^{18}$ & 2006 & China & Primary off-pump coronary artery bypass graft & $\begin{array}{l}\text { Low-dose aprotinin }(n=36) \\
\text { v. placebo }(n=40)\end{array}$ \\
\hline Parvizi et al. ${ }^{25}$ & 2007 & Iran & Primary coronary artery bypass graft, valve & $\begin{array}{l}\text { Low-dose aprotinin }(n=81) \\
\text { v. placebo }(n=81)\end{array}$ \\
\hline Fergusson et al. $^{13}$ & 2008 & Canada & $\begin{array}{l}\text { Repeat coronary artery bypass graft, isolated } \\
\text { mitral valve replacement, combined valve, } \\
\text { multiple valve replacement and repair, } \\
\text { ascending aorta or aortic arch }\end{array}$ & $\begin{array}{l}\text { High-dose aprotinin }(n=781) \\
\text { v. tranexamic acidף }(n=770) \\
\text { v. epsilon aminocaproic acid** } \\
(n=780)\end{array}$ \\
\hline
\end{tabular}

*Pump prime $=2 \times 10^{6}$ Kallikrein inhibitor units (KIU) added to the pump prime.

tHigh dose $=2 \times 10^{6} \mathrm{KIU}$ at induction, $2 \times 10^{6} \mathrm{KIU}$ added to the pump prime, $2 \times 10^{6} \mathrm{KIU}$ or $500000 \mathrm{KIU} / \mathrm{hr}$ continuous infusion during operation

fLow dose $=$ less than $3 \times 10^{6} \mathrm{KIU}$ total dose.

§Total does of tranexamic acid $1-4 \mathrm{~g}$.

१Tranexamic acid regimen: $30 \mathrm{mg} / \mathrm{kg}$ loading dose, $16 \mathrm{mg} / \mathrm{kg}$ maintenance dose, $2 \mathrm{mg} / \mathrm{kg}$ added to the pump prime.

**Epsilon aminocaproic acid regimen: $10 \mathrm{~g}$ loading dose, $2 \mathrm{~g}$ maintenance infusion. 
tions. Mortality was reported in $19(61 \%)$ trials of tranexamic acid, which included a total of 1802 (69\%) participants. Thirteen trials, with a total of 3537 participants, compared aprotinin directly with tranexamic acid and re- ported the number of deaths. Eleven trials, with a total of 3252 participants, recorded myocardial infarctions. In comparison, 15 trials that compared aprotinin and tranexamic acid, with a total of 3528 participants, reported the number

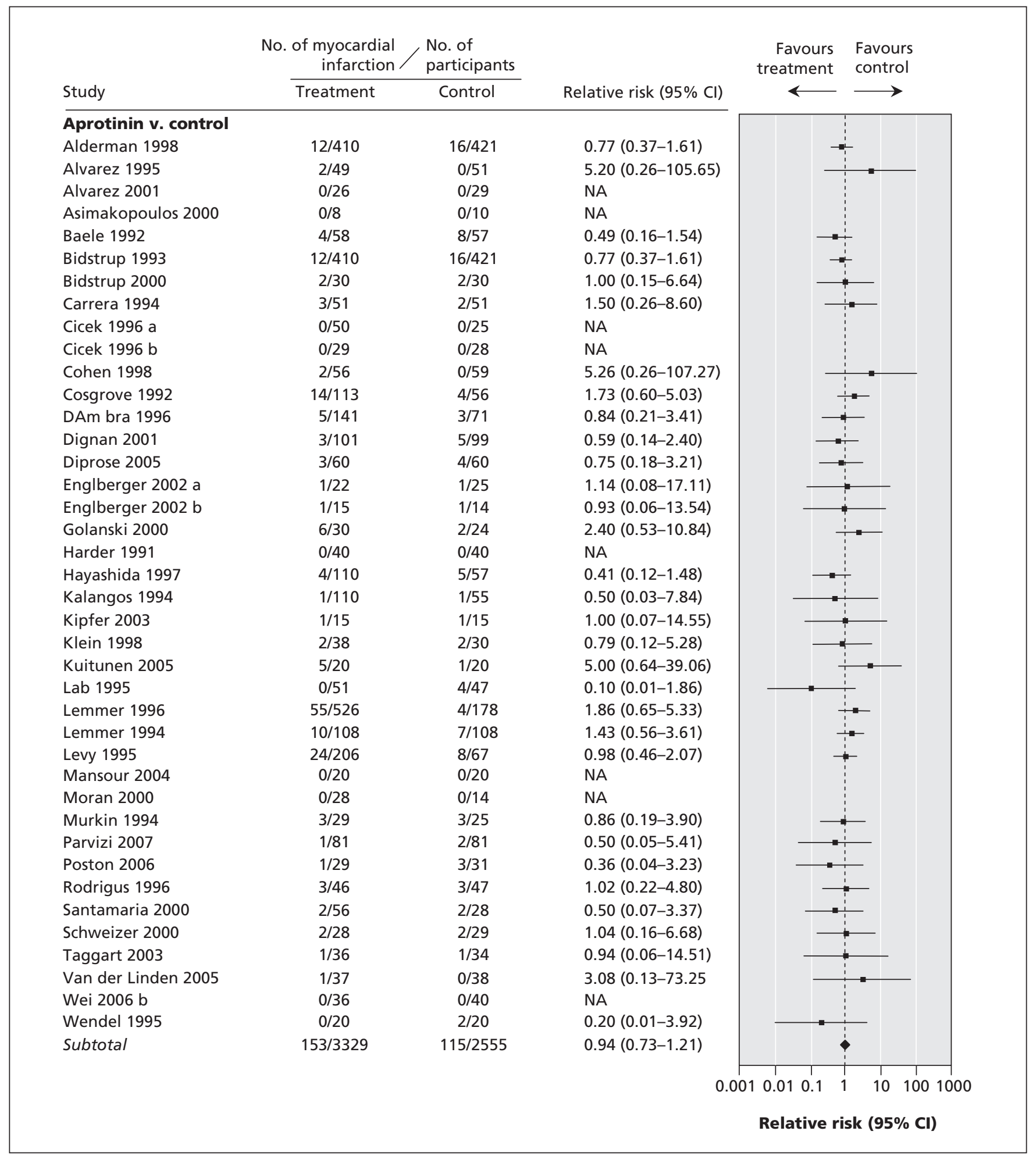

Figure 2: Meta-analyses of myocardial infarction in placebo or inactive randomized controlled trials of the use of aprotinin in cardiac surgery $\left(I^{2}=0 \%, Z=0.46\right)$. References available in Appendix 1 (www.cmaj.ca/cgi/content/full/180/2/183/DC2). Note: $\mathrm{Cl}=$ confidence interval, NA = not applicable. 
of blood transfusions. Thus, the reporting of the number of deaths and myocardial infarctions in the head-to-head trials of aprotinin and tranexamic acid was virtually complete. Data on deaths and myocardial infarction in the trials that included epsilon aminocaproic acid were sparse. From the 5 placebo or inactive controlled trials that included data on deaths (672 patients), there were 10 deaths reported. The head-to-head comparison of epsilon aminocaproic acid with aprotinin was dominated by 1 large trial. ${ }^{13}$

\section{Blood transfusions and reoperation because of bleeding}

Compared with no active treatment, all 3 drugs reduced the number of allogeneic blood transfusions (aprotinin RR $0.66,95 \%$ CI $0.61-0.72$; tranexamic acid $0.70,95 \%$ CI $0.61-0.80$, epsilon aminocaproic acid $0.75,95 \% \mathrm{CI}$ 0.58-0.96). These drugs also reduced the need for reoperation because of continued or recurrent bleeding, although this effect was only statistically significant for aprotinin (aprotinin RR 0.48, 95\% CI 0.34-0.67; tranexamic acid 0.67, 95\% CI 0.41-1.12; epsilon aminocaproic acid 0.35 , 95\% CI 0.11-1.17).

Indirect comparisons suggested that there was no difference between aprotinin, tranexamic acid and epsilon aminocaproic acid in reducing the need for allogeneic blood transfusion (aprotinin v. tranexamic acid RR 0.94, 95\% CI 0.80-1.11; aprotinin v. epsilon aminocaproic acid RR 1.0, 95\% CI 0.81-1.27). The need for reoperation was not significantly reduced with the use of aprotinin compared with the use of tranexamic acid (RR $0.71,95 \%$ CI $0.39-1.31$ ) or epsilon aminocaproic acid (RR 1.37, 95\% CI 0.40-4.7).

In contrast, when the use of aprotinin and tranexamic acid or epsilon aminocaproic acid were directly compared, aprotinin reduced the need for allogeneic transfusion (aprotinin v. tranexamic acid RR 0.87, 95\% CI 0.72-1.03; aprotinin v. epsilon aminocaproic acid RR $0.81,95 \%$ CI $0.75-0.88)$. The use of aprotinin also reduced the need for reoperation (aprotinin v. tranexamic acid RR 0.74 , 95\% CI 0.54-1.02; apro-

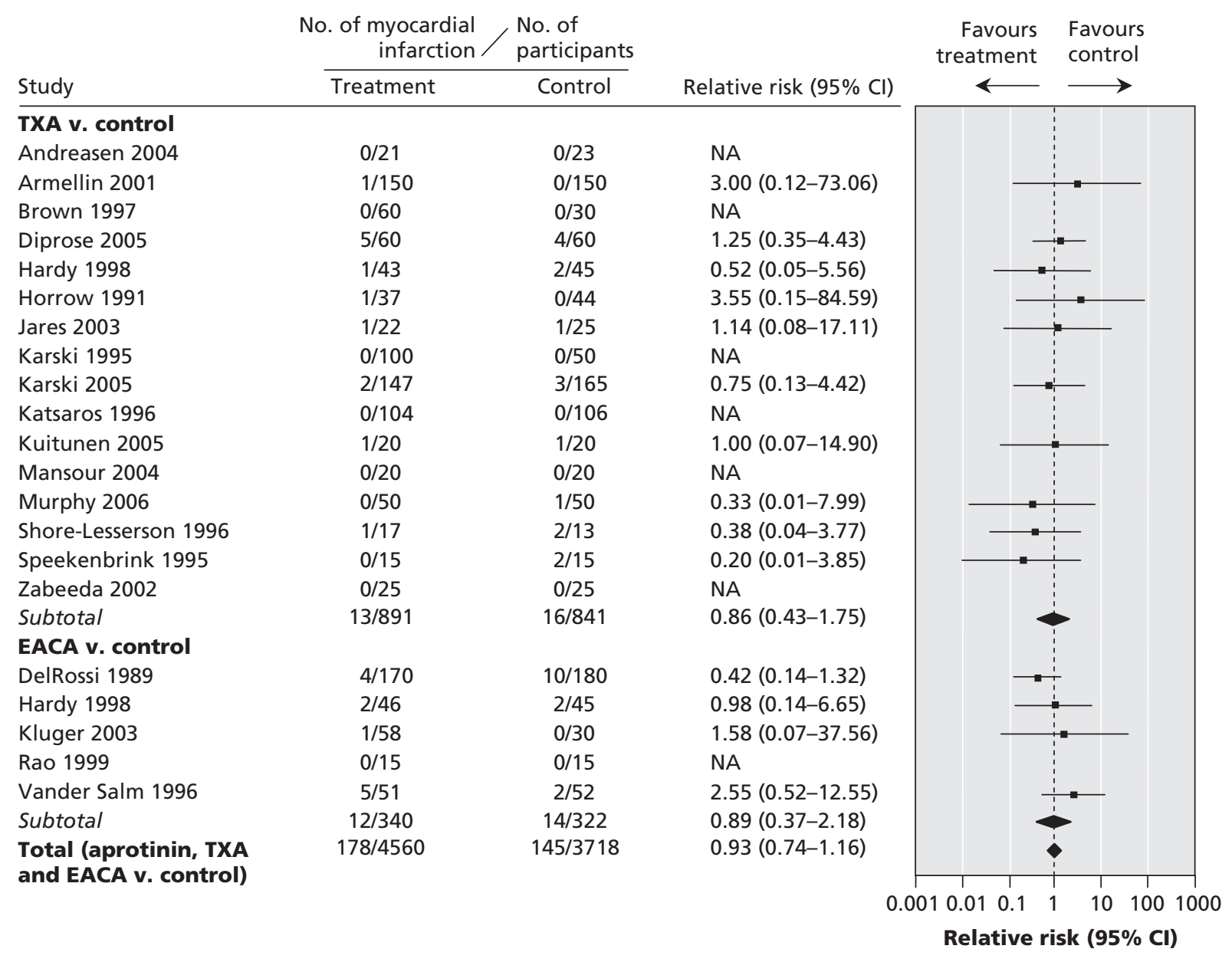

Figure 3: Meta-analyses of myocardial infarction in placebo or inactive randomized controlled trials of the use of tranexamic acid (TXA) and epsilon aminocaproic acid (EACA) in cardiac surgery (TXA v. control $P=0 \%, Z=0.41$; EACA v. control $P^{2}=12.4 \%, Z=0.25$; aprotinin, TXA and EACA v. control $R^{2}=0 \%, Z=0.66$ ). References available in Appendix 1 (www.cmaj.ca/cgi/content/full/180/2/183/DC2). Note: $\mathrm{Cl}=$ confidence interval, $\mathrm{NA}=$ not applicable. 
tinin v. epsilon aminocaproic acid RR 0.72, 95\% CI 0.51-1.03). These direct comparisons were heavily influenced by the inclusion of 1 large trial. ${ }^{13}$

\section{Myocardial infarction}

In total, 81 placebo or inactive controlled trials of the use of aprotinin included 9139 participants. Of these, 40 trials reported 268 myocardial infarctions in 5884 participants (summary RR 0.94, 95\% CI 0.73-1.21) (Figure 2). The RR from the 16 placebo or inactive controlled trials that included tranexamic acid (1732 participants) was 0.86 (95\% CI 0.43-1.75), and the RR from 5 trials that included epsilon aminocaproic acid (662 participants) was 0.89 (95\% CI 0.37-2.18) (Figure 3).

In the indirect comparison of aprotinin with tranexamic acid or epsilon aminocaproic acid, the RR for myocardial infarction was 1.1 (95\% CI 0.52-2.3) for tranexamic acid and 1.1 (95\% CI 0.42-2.7) for epsilon aminocaproic acid.

There were 11 head-to-head trials that compared aprotinin with tranexamic acid, which included a total of 3252 participants and reported 123 myocardial infarctions (Figure 4). There was no difference in the risk of myocardial infarction with the use of aprotinin or tranexamic acid (summary RR 1.0, 95\% CI 0.71-1.43). Only 3 trials compared the use of aprotinin and epsilon aminocaproic acid. These trials included a total of 1617 participants and reported 69 myocardial infarctions, and there was no difference in the risk of myocardial infarction (summary RR 1.17, 95\% CI 0.74-1.86). These analyses were heavily influenced by the results of the BART study. ${ }^{13}$ This study accounted for $51 \%$ of the statistical weight in the comparison of aprotinin and tranexamic acid and $88 \%$ of the weight in the comparison of aprotinin and epsilon aminocaproic acid.

\section{Mortality}

Forty-nine trials of aprotinin, which included 7439 participants, reported 182 deaths. The summary RR for death with the use of aprotinin compared with the use of a placebo or an inactive control was 0.93 (95\% CI 0.69-1.25) (Figure 5). The results were not different when the analysis was restricted to the 11 trials that included more than 100 patients in the aprotinin group (5030 participants total, average of 260 patients in the aprotinin group, 140 deaths total) (summary RR $0.90,95 \%$ CI $0.64-1.28$ ). All but 2 of the larger trials $^{26,27}$ recruited patients at high risk of perioperative mortality (second or subsequent revascularization procedure, valve surgery or combined procedures). The observed effects of aprotinin were not related to trial quality, as reflected in the adequacy of allocation concealment.

There were 31 trials that compared tranexamic acid with placebo, with a total of 2617 participants. Of these trials, 19 (1802 participants) reported 24 deaths (summary RR 0.55 , 95\% CI 0.24-1.25) (Figure 6). Five trials of epsilon aminocaproic acid included a total of 672 participants with a total of 10 deaths (summary RR 1.65, 95\% CI 0.50-5.43) (Figure 6). The indirect estimate of RR was 1.69 (95\% CI 0.70-4.10 for aprotinin versus tranexamic acid and $0.56(95 \%$ CI 0.16-1.93) for aprotinin versus epsilon aminocaproic acid.

Thirteen trials compared aprotinin directly with tranexamic acid (3537 participants). There were 107 deaths reported in these trials (Figure 7). The summary RR for death with the use of aprotinin versus tranexamic acid was 1.43 (95\% CI 0.98-2.08). Four trials compared the use of aprotinin and epsilon aminocaproic acid. These trials included 1840 participants and reported 85 deaths. The RR for death with the use of aprotinin versus epsilon aminocaproic acid was 1.49 (95\% CI 0.98-2.28) (Figure 8). These analyses

\begin{tabular}{|c|c|c|c|c|c|}
\hline Study & $\begin{array}{c}\begin{array}{c}\text { No. of myocardial } \\
\text { infarction }\end{array} \\
\text { Aprotinin }\end{array}$ & $\begin{array}{l}\text { No. of } \\
\text { participants } \\
\text { TXA }\end{array}$ & Relative risk $(95 \% \mathrm{Cl})$ & \multicolumn{2}{|c|}{ 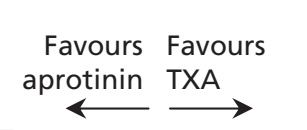 } \\
\hline Bernet 1999 & $0 / 28$ & $0 / 28$ & NA & & \\
\hline Mansour 2004 & $0 / 20$ & $0 / 20$ & NA & & \\
\hline Speekenbrink 1995 & $1 / 15$ & $0 / 15$ & $3.00(0.13-68.26)$ & & $\rightarrow$ \\
\hline Kuitunen 2005 & $5 / 20$ & $1 / 20$ & $5.00(0.64-39.06)$ & & $\longrightarrow$ \\
\hline Mongan 1998 & $2 / 75$ & $3 / 75$ & $0.67(0.11-3.88)$ & $\longrightarrow$ & $:$ \\
\hline Hekmat 2004 & $2 / 60$ & $4 / 58$ & $0.48(0.09-2.54)$ & $\longrightarrow$ & \begin{tabular}{c}
1 \\
\hdashline
\end{tabular} \\
\hline Casati 1999 & $3 / 67$ & $4 / 70$ & $0.78(0.18-3.37)$ & $\longrightarrow$ & -1 \\
\hline Diprose 2005 & $3 / 60$ & $5 / 60$ & $0.60(0.15-2.40)$ & $\longrightarrow$ & $\frac{1}{1}$ \\
\hline Wong 2000 & $4 / 39$ & $5 / 38$ & $0.78(0.23-2.68)$ & $\longrightarrow$ & - \\
\hline Casati 2000 & $9 / 518$ & $11 / 522$ & $0.82(0.34-1.97)$ & & -1 \\
\hline Fergusson (BART) 2008 & $33 / 717$ & $28 / 727$ & $1.20(0.73-1.96)$ & & - \\
\hline Total & $62 / 1619$ & $61 / 1633$ & $1.00(0.71-1.43)$ & & $\bullet$ \\
\hline & & & & 0.010 .1 & $\begin{array}{llll} & & & \\
1 & 10 & 100\end{array}$ \\
\hline & & & & Relative $\mathbf{r}$ & isk $(95 \% \mathrm{Cl})$ \\
\hline
\end{tabular}

Figure 4: Meta-analyses of myocardial infarction in head-to-head randomized controlled trials of the use of aprotinin and tranexamic acid (TXA) in cardiac surgery $\left(I^{2}=0 \%, Z=0.02\right)$. References available in Appendix 1 (www.cmaj.ca/cgi/content/full/180/2/183/DC2). Note: $\mathrm{Cl}=$ confidence interval, $\mathrm{NA}=$ not applicable. 


\begin{tabular}{|c|c|c|c|}
\hline \multirow[b]{2}{*}{ Study } & \multicolumn{2}{|c|}{$\begin{array}{l}\text { No. of } \\
\text { deaths }\end{array} / \begin{array}{l}\text { No. of } \\
\text { participants }\end{array}$} & \multirow[b]{2}{*}{ Relative risk $(95 \% \mathrm{Cl})$} \\
\hline & Treatment & Control & \\
\hline \multicolumn{4}{|l|}{ Aprotinin v. control } \\
\hline Alderman 1998 & $6 / 436$ & $7 / 434$ & $0.85(0.29-2.52)$ \\
\hline Alvarez 1995 & $1 / 49$ & $0 / 51$ & $3.12(0.13-78.80)$ \\
\hline Alvarez 2001 & $0 / 26$ & $0 / 29$ & NA \\
\hline Ashraf 1997 & $0 / 19$ & $0 / 19$ & NA \\
\hline Bidstrup 1989 & $0 / 40$ & $1 / 40$ & $0.33(0.01-7.95)$ \\
\hline Bidstrup 1993 & $2 / 43$ & $0 / 47$ & $5.45(0.27-110.51)$ \\
\hline Bidstrup 2000 & $1 / 30$ & $0 / 30$ & $3.00(0.13-70.83)$ \\
\hline Blauhut 1994 & $1 / 14$ & $1 / 14$ & $3.00(0.13-67.91)$ \\
\hline Casas 1995 & $2 / 47$ & $1 / 51$ & $2.17(0.20-23.16)$ \\
\hline Cicekcioglu 2006 & $0 / 24$ & $0 / 20$ & NA \\
\hline Cohen 1998 & $2 / 56$ & $0 / 59$ & $5.26(0.26-107.27)$ \\
\hline Cosgrove 1992 & $9 / 113$ & $4 / 56$ & $1.12(0.36-3.46)$ \\
\hline D'Ambra 1996 & $5 / 141$ & $0 / 71$ & $5.58(0.31-99.47)$ \\
\hline Dietrich 1992 & $24 / 902$ & $31 / 882$ & $0.76(0.45-1.28)$ \\
\hline Dietrich 1995 & $0 / 15$ & $2 / 15$ & $0.20(0.01-3.85)$ \\
\hline Dignan 2001 & $0 / 101$ & $0 / 99$ & NA \\
\hline Diprose 2005 & $0 / 60$ & $1 / 60$ & $0.33(0.01-8.02)$ \\
\hline Englberger 2002 a & $0 / 22$ & $0 / 25$ & NA \\
\hline Englberger 2002 b & $0 / 15$ & $0 / 14$ & NA \\
\hline Feindt 1994 & $0 / 10$ & $0 / 10$ & NA \\
\hline Golanski 2000 & $1 / 30$ & $0 / 24$ & $2.42(0.10-56.85)$ \\
\hline Gott 1998 & $2 / 109$ & $4 / 112$ & $0.51(0.10-2.75)$ \\
\hline Green 1995 & $1 / 48$ & $1 / 36$ & $0.75(0.05-11.59)$ \\
\hline Hardy 1993 & $0 / 22$ & $2 / 22$ & $0.20(0.01-3.94)$ \\
\hline Hayashida 1997 & $1 / 110$ & $2 / 57$ & $0.26(0.02-2.80)$ \\
\hline Jamieson 1997 & $1 / 24$ & $0 / 36$ & $4.44(0.19-104.67)$ \\
\hline Kipfer 2003 & $0 / 15$ & $0 / 15$ & NA \\
\hline Koster 2004 & $0 / 100$ & $0 / 100$ & NA \\
\hline Kuepper 2003 & $0 / 60$ & $0 / 59$ & NA \\
\hline Kuitunen 2005 & $0 / 20$ & $0 / 20$ & NA \\
\hline Kunt 2005 & $0 / 40$ & $0 / 46$ & NA \\
\hline Lab 1995 & $0 / 51$ & $2 / 47$ & $0.18(0.01-3.75)$ \\
\hline Lemmer 1996 & $12 / 526$ & $3 / 178$ & $1.35(0.39-4.47)$ \\
\hline Lemmer 1994 & $6 / 108$ & $4 / 108$ & $1.50(0.44-5.17)$ \\
\hline Levy 1995 & $15 / 215$ & $5 / 72$ & $1.00(0.38-2.67)$ \\
\hline Liu 1993 & $0 / 20$ & $1 / 20$ & $0.33(0.01-7.72)$ \\
\hline Maccario 1994 & $1 / 61$ & $0 / 32$ & $1.60(0.07-38.11)$ \\
\hline Misfeld 1998 & $0 / 14$ & $0 / 14$ & NA \\
\hline Mohr 1992 & $0 / 34$ & $0 / 16$ & NA \\
\hline Moran 2000 & $0 / 28$ & $0 / 14$ & NA \\
\hline Nuttall 2000 & $0 / 45$ & $2 / 45$ & $0.20(0.01-4.05)$ \\
\hline Rocha 1994 & $0 / 28$ & $0 / 28$ & NA \\
\hline Rodrigus 1996 & $1 / 46$ & $2 / 47$ & $0.51(0.05-5.44)$ \\
\hline Royston 1987 & $0 / 11$ & $1 / 11$ & $0.33(0.02-7.39)$ \\
\hline Schweizer 2000 & $1 / 28$ & $0 / 29$ & $3.10(0.13-73.12)$ \\
\hline Stammers 1997 & $1 / 8$ & $0 / 12$ & $4.33(0.20-94.83)$ \\
\hline Swart 1994 & $2 / 49$ & $4 / 49$ & $0.50(0.10-2.60)$ \\
\hline Van der Linden 2005 & $3 / 37$ & $1 / 38$ & $3.08(0.34-28.30)$ \\
\hline Wei 2006 b & $0 / 36$ & $0 / 40$ & NA \\
\hline Subtotal & $101 / 4086$ & $81 / 3353$ & $0.93(0.69-1.25)$ \\
\hline
\end{tabular}

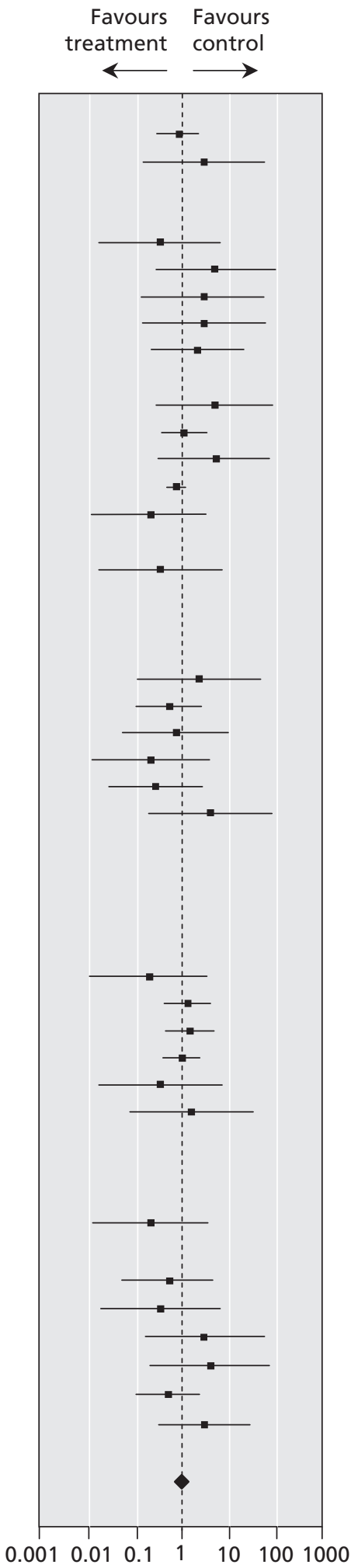

Relative risk $(95 \% \mathrm{Cl})$

Figure 5: Meta-analyses of mortality in randomized placebo or inactive controlled trials of aprotinin $\left(R^{2}=0 \%, Z=0.49\right)$. References available in Appendix 1 (www.cmaj.ca/cgi/content/full/180/2/183/DC2). Note: $\mathrm{Cl}=$ confidence interval, NA = not applicable. 
were dominated by the inclusion of 1 large trial,,$^{13}$ which accounted for $71 \%$ of the statistical weight in the comparison of aprotinin and tranexamic acid and $91 \%$ in the comparison of aprotinin and epsilon aminocaproic acid. None of the other new trials included in this updated review contributed significant statistical weight to the analysis of the direct comparisons.

We found no significant heterogeneity in any of the metaanalyses of myocardial infarctions or deaths.

\section{Interpretation}

We found that there was a moderate increase in the risk of death among patients who received aprotinin. Although all confidence intervals for mortality included 1, the results were consistent in both direct and indirect comparisons. It appears that metaanalyses of direct and indirect comparisons agree that aprotinin increases the risk of death compared to lysine analogues. How- ever, this conclusion is not as clear if we consider the clinical events that might cause an increase in the risk of death. Although there was an increase in cardiac death among patients who received aprotinin in the BART study, there was no increase in myocardial infarction, stroke or renal failure either in this trial or in our indirect and direct comparison meta-analyses. In addition, both our 2007 review and our current meta-analyses comparing aprotinin with placebo did not show increased mortality. ${ }^{2}$ These meta-analyses also did not show increases in myocardial infarction, stroke, or renal dysfunction or failure. ${ }^{2}$

Ray and Stein ${ }^{7}$ suggested that the failure to detect an increase in death in the placebo controlled trials of aprotinin in our 2007 meta-analysis may have been because of underreporting of infrequent events that were not the primary outcomes of small trials. However, deaths were reported in most of these trials, and the mortality analysis included more than $80 \%$ of the patients included in all eligible placebo controlled trials of aprotinin. To account for the

\begin{tabular}{|c|c|c|c|c|c|}
\hline \multirow[b]{2}{*}{ Study } & \multicolumn{2}{|c|}{$\begin{array}{l}\text { No. of } \\
\text { deaths }\end{array} / \begin{array}{l}\text { No. of } \\
\text { participants }\end{array}$} & \multirow[b]{2}{*}{ Relative risk $(95 \% \mathrm{Cl})$} & \multirow{2}{*}{$\begin{array}{r}\text { Favours } \\
\text { treatment } \\
\longleftarrow\end{array}$} & \multirow{2}{*}{$\begin{array}{l}\text { Favours } \\
\text { control } \\
\longrightarrow\end{array}$} \\
\hline & Treatment & Control & & & \\
\hline \multicolumn{6}{|l|}{ TXA v. control } \\
\hline Andreasen 2004 & $1 / 21$ & $0 / 23$ & $3.27(0.14-76.21)$ & & $\rightarrow$ \\
\hline Armellin 2001 & $1 / 150$ & $3 / 150$ & $0.33(0.04-3.17)$ & - & \\
\hline Blauhut 1994 & $0 / 15$ & $0 / 14$ & NA & & \\
\hline Brown 1997 & $1 / 60$ & $0 / 30$ & $1.52(0.06-36.34)$ & & \\
\hline Coffey 1995 & $0 / 16$ & $1 / 14$ & $0.29(0.01-6.69)$ & - & - \\
\hline Diprose 2005 & $0 / 60$ & $1 / 60$ & $0.33(0.01-8.02)$ & 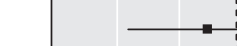 & \\
\hline Dryden 1997 & $1 / 22$ & $4 / 19$ & $0.22(0.03-1.77)$ & $=$ & \\
\hline Hardy 1998 & $0 / 43$ & $0 / 45$ & NA & & \\
\hline Jares 2003 & $0 / 22$ & $0 / 25$ & NA & & \\
\hline Karski 2005 & $3 / 147$ & $1 / 165$ & $3.37(0.35-32.02)$ & & \\
\hline Katoh 1997 & $1 / 62$ & $0 / 31$ & $1.52(0.06-36.36)$ & & \\
\hline Katsaros 1996 & 0/104 & $2 / 106$ & $0.20(0.01-4.19)$ &. & - \\
\hline Kuitunen 2005 & $0 / 20$ & $0 / 20$ & NA & & \\
\hline Misfeld 1998 & $0 / 14$ & $0 / 14$ & NA & & \\
\hline Murphy 2006 & $0 / 50$ & $0 / 50$ & NA & & \\
\hline Nuttall 2000 & $0 / 45$ & $2 / 45$ & $0.20(0.01-4.05)$ & - & \\
\hline Santos 2006 & $0 / 25$ & $2 / 31$ & $0.21(0.01-4.26)$ & & \\
\hline Shore-Lesserson 1996 & $0 / 17$ & $0 / 13$ & NA & & \\
\hline Zabeeda 2002 & $0 / 25$ & $0 / 25$ & NA & & \\
\hline Subtotal & $8 / 922$ & $16 / 880$ & $0.55(0.24-1.25)$ & & \\
\hline \multicolumn{6}{|l|}{ EACA v. control } \\
\hline Daily 1994 & $0 / 21$ & $0 / 19$ & NA & & \\
\hline DelRossi 1989 & $3 / 170$ & $3 / 180$ & $1.06(0.22-5.17)$ & & - \\
\hline Hardy 1998 & $2 / 46$ & $0 / 45$ & $4.89(0.24-99.18)$ & & 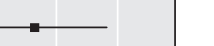 \\
\hline Kluger 2003 & $1 / 58$ & $0 / 30$ & $1.58(0.07-37.56)$ & & \\
\hline Vander Salm 1996 & $1 / 51$ & $0 / 52$ & $3.06(0.13-73.36)$ & & \\
\hline Subtotal & $7 / 346$ & $3 / 326$ & $1.65(0.50-5.43)$ & & \\
\hline \multirow{3}{*}{$\begin{array}{l}\text { Total (aprotinin, TXA } \\
\text { and EACA v. control) }\end{array}$} & $116 / 5354$ & $100 / 4559$ & $0.90(0.69-1.19)$ & & \\
\hline & & & & 0.0010 .010 .1 & 101001000 \\
\hline & & & & \multicolumn{2}{|c|}{ Relative risk $(95 \% \mathrm{Cl})$} \\
\hline
\end{tabular}

Figure 6: Meta-analyses of mortality in randomized placebo or inactive controlled trials of tranexamic acid (TXA) and epsilon aminocaproic acid (EACA) (TXA v. control $l^{2}=0 \%, Z=1.43$; EACA v. control $P^{2} 0 \%, Z=0.83$; aprotinin, TXA and EACA v. control $l^{2}=0 \%, Z=0.73$. References available in Appendix 1 (www.cmaj.ca/cgi/content/full/180/2/183/DC2). Note: $\mathrm{Cl}=$ confidence interval, NA = not applicable. 
possibility that underreporting of deaths in small trials diluted an adverse effect of aprotinin, we restricted our analysis to the 11 largest placebo controlled trials. These trials included more than 100 patients in the aprotinin arms. All but 2 of these trials included patients at high risk of death (defined as those having their second or subsequent revascularization procedure, valve surgery or combined procedures). Thus, the participants in these trials were similar to those in the recently published BART study. However, the sensitivity analysis of larger trials with predominantly high-risk patients found no increase in death with the use of aprotinin compared to use of an inactive control. We accept that death after admission to hospital is seldom reported in these trials, and we may have missed a late effect. However, in the largest comparative trial, the separation in survival curves occurred early and the curves appear parallel from 5 to 30 days after surgery. ${ }^{13}$ The observational study by Schneeweiss and colleagues also found an early increase in mortality with use of aprotinin. ${ }^{9}$

The use of tranexamic acid appeared to reduce mortality; however, the effect was not statistically significant. As a consequence, the increased relative risk of death seen in the indirect comparison of aprotinin and tranexamic acid is because of lower mortality with the use of tranexamic acid, rather than

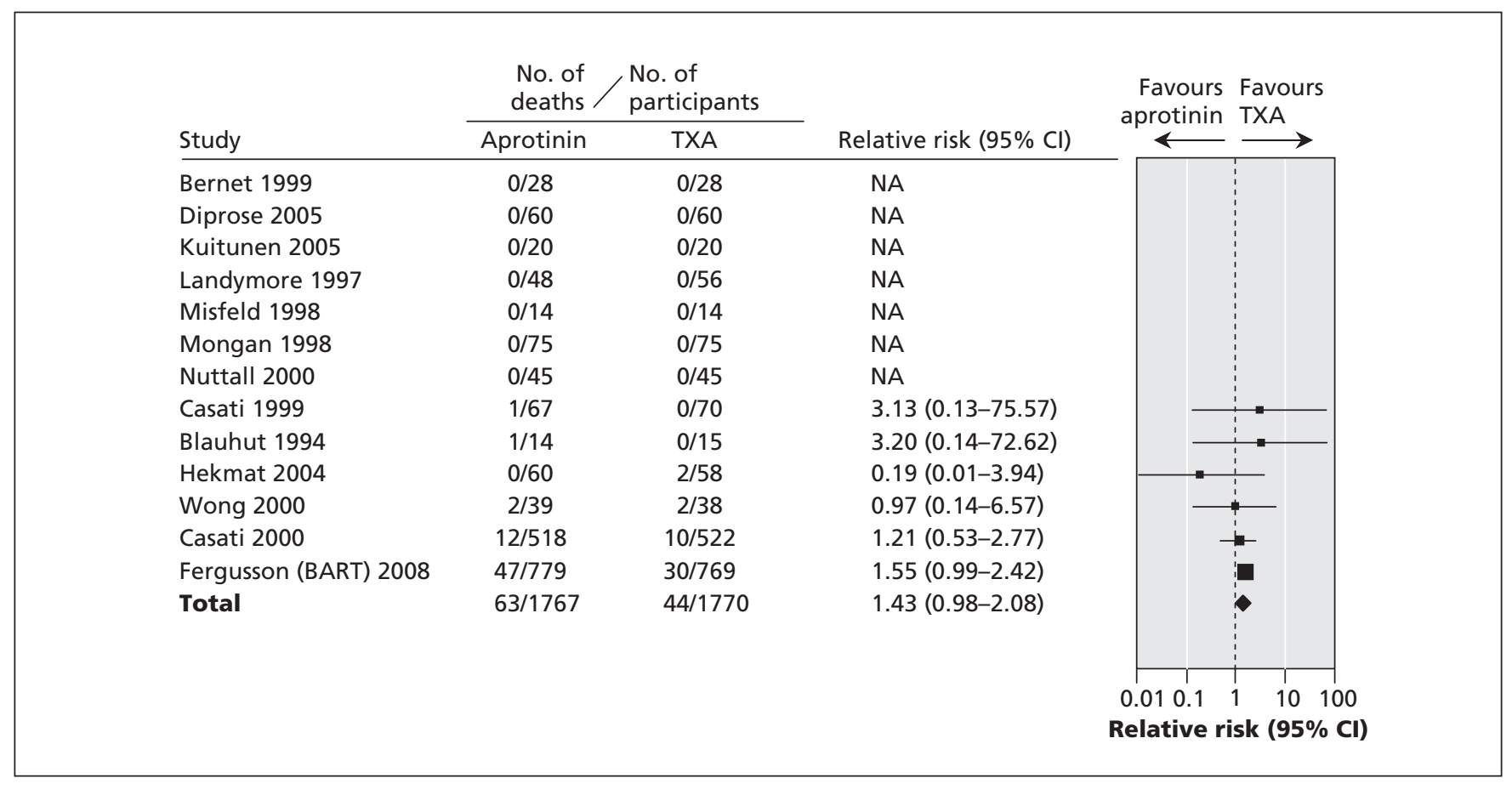

Figure 7: Meta-analyses of mortality in head-to-head randomized controlled trials of the use of aprotinin and tranexamic acid (TXA) in cardiac surgery $\left(I^{2}=0 \%, Z=1.85\right)$. References available in Appendix 1 (www.cmaj.ca/cgi/content/full/180/2/183/DC2). Note: $\mathrm{Cl}=$ confidence interval, NA = not applicable.

\begin{tabular}{|c|c|c|c|c|c|}
\hline \multirow[b]{2}{*}{ Study } & \multicolumn{2}{|c|}{$\begin{array}{c}\text { No. of } \\
\text { deaths }\end{array} / \begin{array}{l}\text { No. of } \\
\text { participants }\end{array}$} & \multirow{2}{*}{\multicolumn{2}{|c|}{$\begin{array}{l}\text { Favours } \\
\text { aprotinin }\end{array}$}} & \multirow{2}{*}{$\begin{array}{l}\text { Favours } \\
\stackrel{\text { EACA }}{\longrightarrow}\end{array}$} \\
\hline & Aprotinin & EACA & & & \\
\hline Landymore 1997 & $0 / 48$ & $0 / 44$ & NA & & \\
\hline Casati 1999 & $1 / 67$ & $1 / 66$ & $0.99(0.06-15.42)$ & & \\
\hline Trinh-Duc 1992 & $3 / 29$ & $2 / 27$ & $1.40(0.25-7.73)$ & & - \\
\hline Fergusson (BART) 2008 & $47 / 779$ & $31 / 780$ & $1.52(0.98-2.36)$ & & 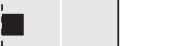 \\
\hline Total & $51 / 923$ & $34 / 917$ & $1.49(0.98-2.28)$ & & 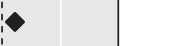 \\
\hline & & & & 0.010 .1 & 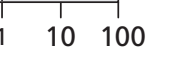 \\
\hline & & & & Relative ri & sk $(95 \% \mathrm{CI})$ \\
\hline
\end{tabular}

Figure 8: Meta-analyses of mortality in head-to-head randomized controlled trials of the use of aprotinin and epsilon aminocaproic acid (EACA) in cardiac surgery $\left(I^{2}=0 \%, Z=1.86\right)$. References available in Appendix 1 (www.cmaj.ca/cgi/content/full/180/2/183/DC2). Note: $C l=$ confidence interval, NA = not applicable. 
an adverse effect of aprotinin. In contrast to aprotinin and tranexamic acid, the indirect and direct comparisons of mortality between aprotinin and epsilon aminocaproic acid gave qualitatively different results (RR 0.56 and 1.49 respectively, neither of which was statistically significant). However, there were only 7 deaths reported in the epsilon aminocaproic acid group and 3 in the control group, which makes the results of the indirect comparisons unstable and unreliable.

In our 2007 Cochrane review, ${ }^{2}$ we addressed the issue of heterogeneity, which will not be discussed at length here. Briefly, we found significant heterogeneity among the trials of antifibrinolytic drugs in cardiac surgery that included bleeding and the need for transfusion as clinical outcomes. However, there was no significant heterogeneity among trials that included clinical outcomes (surgery for re-bleeding, myocardial infarction and death). The heterogeneity for bleeding outcomes is likely because of the subjective nature of clinical judgment about blood loss and need for transfusion against a background of often unblinded trials. Varying drug doses could also have contributed to heterogeneity in bleeding outcomes.

As reported in our Cochrane review, ${ }^{2}$ we found evidence of publication bias in the trials of aprotinin, which led to a probable overestimation of the blood sparing effect of aprotinin. However, we did not find publication bias in relation to the clinical outcomes of death and myocardial infarction.

Several controlled observational studies have examined the putative adverse effects of aprotinin. One large observational study by Mangano and colleagues ${ }^{28}$ which found an approximate $50 \%$ relative increase in 5-year mortality with use of aprotinin, was criticized for being based on registry data and because of the possibility that selection bias (the use of aprotinin in high-risk patients) might have confounded the association between use of aprotinin and adverse effects. ${ }^{7,11,12}$ Later studies, which appear to have been better controlled than the study by Mangano and colleagues, reported a lower but still elevated risk of death from all causes when the use of aprotinin was compared to lysine analogues or placebo., ${ }^{9} 10$ The overall relative risk for death was similar to that observed in the BART study and to the results of the direct and indirect meta-analyses in this article. However, the latter analyses found no increase in stroke, myocardial infarction or renal failure, in contrast to the results of observational studies..$^{10,28}$

\section{Limitations}

The main limitation of this meta-analysis is the relatively small number of deaths and myocardial infarctions. Even with the addition of the BART study, there were only 63 deaths among patients who received aprotinin and 44 deaths among those who received tranexamic acid in the head-to-head trials. None of these trials was designed to measure changes in the rates of death and thrombosis, and underreporting of adverse events may, in part, account for our previous failure to detect an increase in mortality. Thus, although the trend toward increased mortality among those who received aprotinin compared with those who received a lysine analogue is worrying (and convinced the data safety monitoring board and investigators of the BART study to stop randomly allocating patients to receive aprotinin), this meta-analysis should not be interpreted as providing definitive evidence that aprotinin increases the risk of death. However, because of evidence that lysine analogues decrease the frequency of transfusion compared with no treatment, as well as their lower cost and the increased mortality with use of aprotinin, it is unlikely that another large randomized trial will be designed to directly compare mortality with use of these drugs.

\section{Conclusions}

The conclusions of our updated review conflict with those of our published Cochrane review. ${ }^{2}$ In our 2007 review, we included trials that compared the use of antifibrinolytic drugs in all types of surgery, not just cardiac procedures. Our conclusions about the safety of antifibrinolytic drugs compared with placebo or no treatment remains the same - there was no increase in the risk of death or myocardial infarction in either review.

However, there is an important change in the conclusion based on the results of the direct comparisons of aprotinin, tranexamic acid and epsilon aminocaproic acid. The addition of data from the BART study increased the relative risk of death with the use of aprotinin compared with the use of either tranexamic acid or epsilon aminocaproic acid. The balance of evidence now favours the use of lysine analogues over aprotinin. This represents a shift in the conclusions of our Cochrane review, which was last updated in 2007. ${ }^{2}$ Compared with aprotinin, lysine analogues are almost as effective, are cheaper and do not appear to increase mortality.

This article has been peer reviewed.

Competing interests: Dean Fergusson was a principal investigator of the BART trial. Andreas Laupacis was chair of the BART Data Safety Monitoring Board. None declared for David Henry or Paul Carless.

Paul Hébert, editor-in-chief of $C M A J$, was a principal investigator of the BART trial. He was not involved in the editorial decision-making process for this article.

Contributors: All of the authors contributed substantially to the study conception and design. Paul Carless and Dean Fergusson were responsible for the data acquisition and analyses. David Henry and Paul Carless wrote the draft manuscript. All of the authors contributed to the interpretation of the results and the critical revision of the manuscript. All of the authors approved the version submitted for publication.

Acknowledgement: We thank Annette Moxey for her assistance with data extraction and assessment of study quality.

Funding: No specific funding was obtained for this study.

\section{REFERENCES}

1. Fergusson D, Blair A, Henry D, et al. Technologies to minimise blood transfusion in cardiac and orthopedic surgery: Results of a practice variation survey in ten countries. Int J Technol Assess Health Care 1999;15:717-28.

2. Henry DA, Carless PA, Moxey AJ, et al. Anti-fibrinolytic use for minimising perioperative allogeneic blood transfusion. Cochrane Database Syst Rev 2007;(3): CD001886.

3. Sedrakyan A, Treasure T, Elefteriades J. Effect of aprotinin on clinical outcomes in coronary artery bypass graft surgery: A systematic review and meta-analysis of randomized clinical trials. J Thorac Cardiovasc Surg 2004;128:442-8.

4. Munoz JJ, Birkmeyer NJO, Birkmeyer JD, et al. Is aminocaproic acid as effective as aprotinin in reducing bleeding with cardiac surgery? Circulation 1999;99:81-9.

5. Brown JR, Birkmeyer NJO, O'Connor GT. Meta-analysis comparing the effectiveness and adverse outcomes of antifibrinolytic agents in cardiac surgery. Circulation 2007;115:2801-13. 
6. Carless PA, Moxey AJ, Stokes BJ. Are antifibrinolytic drugs equivalent in reducing blood loss and transfusion in cardiac surgery? A meta-analysis of randomized head-to-head trials. BMC Cardiovasc Disord 2005;5:19.

7. Ray WA, Stein CM. The aprotinin story - Is BART the final chapter? $N$ Engl $J$ Med 2008;358:2398-400.

8. Mangano DT, Miao Y, Vuylsteke A, et al. Mortality associated with aprotinin during 5 years following coronary artery bypass graft surgery. JAMA 2007;297:471-9.

9. Schneeweiss S, Seeger JD, Landon J, et al. Aprotinin during coronary-artery bypass grafting and risk of death. N Engl J Med 2008;358:771-83.

10. Shaw AD, Stafford-Smith M, White WD, et al. The effect of aprotinin on outcome after coronary-artery bypass grafting. N Engl J Med 2008;358:784-93.

11. Levy JH, Ramsay JG, Guyton RA. Aprotinin in cardiac surgery. $N$ Engl J Med 2006:354:1953-7.

12. Bidstrup BP. Aprotinin and tranexamic acid in high-transfusion-risk cardiac surgery. Transfusion 2006;46:2208-10.

13. Fergusson DA, Hébert PC, Mazer CD, et al. A comparison of aprotinin and lysine analogues in high-risk cardiac surgery. $N$ Engl J Med 2008;358:2319-31.

14. Higgins J, Green S, editors. Cochrane handbook for systematic reviews of interventions: version 5.0.1 Oxford (UK): The Cochrane Collaboration; 2008. Available: www.cochrane.org/resources/handbook/index.htm (accessed 2008 Nov 26).

15. Bucher HC, Guyatt GH, Griffith LE, et al. The results of direct and indirect treatment comparisons in meta-analysis of randomized controlled trials. J Clin Epidemiol 1997;50:683-91.

16. Asimakopoulos G, Kohn A, Stefanou DC, et al. Leukocyte integrin expression in patients undergoing cardiopulmonary bypass. Ann Thorac Surg 2000;69:1192-7.

17. Cicekcioglu F, Cagli K, Emir M, et al. Effects of minimal dose aprotinin on blood loss and fibrinolytic system-complement activation in coronary artery bypass grafting surgery. J Card Surg 2006;21:336-41.

18. Wei M, Jian K, Guo Z, et al. Effects of half-dose aprotinin in off-pump coronary artery bypass grafting. World J Surg 2006;30:1108-14.

19. Feindt P, Seyfert U, Volkmer I, et al. Is there a phase of hypercoagulability when aprotinin is used in cardiac surgery? Eur J Cardiothorac Surg 1994;8:308-13.
20. Gott JP, Cooper WA, Schmidt FE, et al. Modifying risk for extracorporeal circulation: trial of four anti-inflammatory strategies. Ann Thorac Surg 1998;66:747-53.

21. Kuitunen AHS. Tranexamic acid does not correct the haemostatic impairment caused by hydroxyethyl starch $(200 \mathrm{kDa} / 0.5)$ after cardiac surgery. Blood Coagul Fibrinolysis 2006;17:639-45.

22. Luo J, Huang Y, Lan H. Effect of aprotinin on the red cell immunity in cardiopulmonary bypass. J Tongji Med Univ 1998;18:97-100.

23. Rhydderch RD, Khan B, Saleh A, et al. Single dose aprotinin in routine cardiac surgery. Middle East J Anesthesiol 1993;12:287-97.

24. Murphy GJ, Mango E, Lucchetti V, et al. A randomized trial of tranexamic acid in combination with cell salvage plus a meta-analysis of randomized trials evaluating tranexamic acid in off-pump coronary artery bypass grafting. J Thorac Cardiovasc Surg 2006;132:475-80.

25. Parvizi R, Azarfarin R, Hassanzadeh S. Ultra-low dose aprotinin effects on reducing the need for blood transfusion in cardiac surgery. Saudi Med J 2007;28:49-53.

26. Lemmer JH Jr, Stanford W, Bonney SL, et al. Aprotinin for coronary bypass operations: efficacy, safety, and influence on early saphenous vein graft patency. A multicenter, randomized, double-blind, placebo-controlled study. J Thorac Cardiovasc Surg 1994;107:543-51

27. Alderman EL, Levy JH, Rich JB, et al. Analyses of coronary graft patency after aprotinin use: results from the International Multicenter Aprotinin Graft Patency Experience (IMAGE) trial. J Thorac Cardiovasc Surg 1998;116:716-30.

28. Mangano DT, Tudor IC, Dietzel C; Multicenter Study of Perioperative Ischemia Research Group; Ischemia Research and Education Foundation. The risk associated with aprotinin in cardiac surgery. $N$ Engl J Med 2006;354:353-65.

Correspondence to: Dr. David Henry, Institute for Clinical Evaluative Sciences, G Wing, Sunnybrook Health Sciences Centre, 2075 Bayview Ave., Toronto ON M4N 3M5

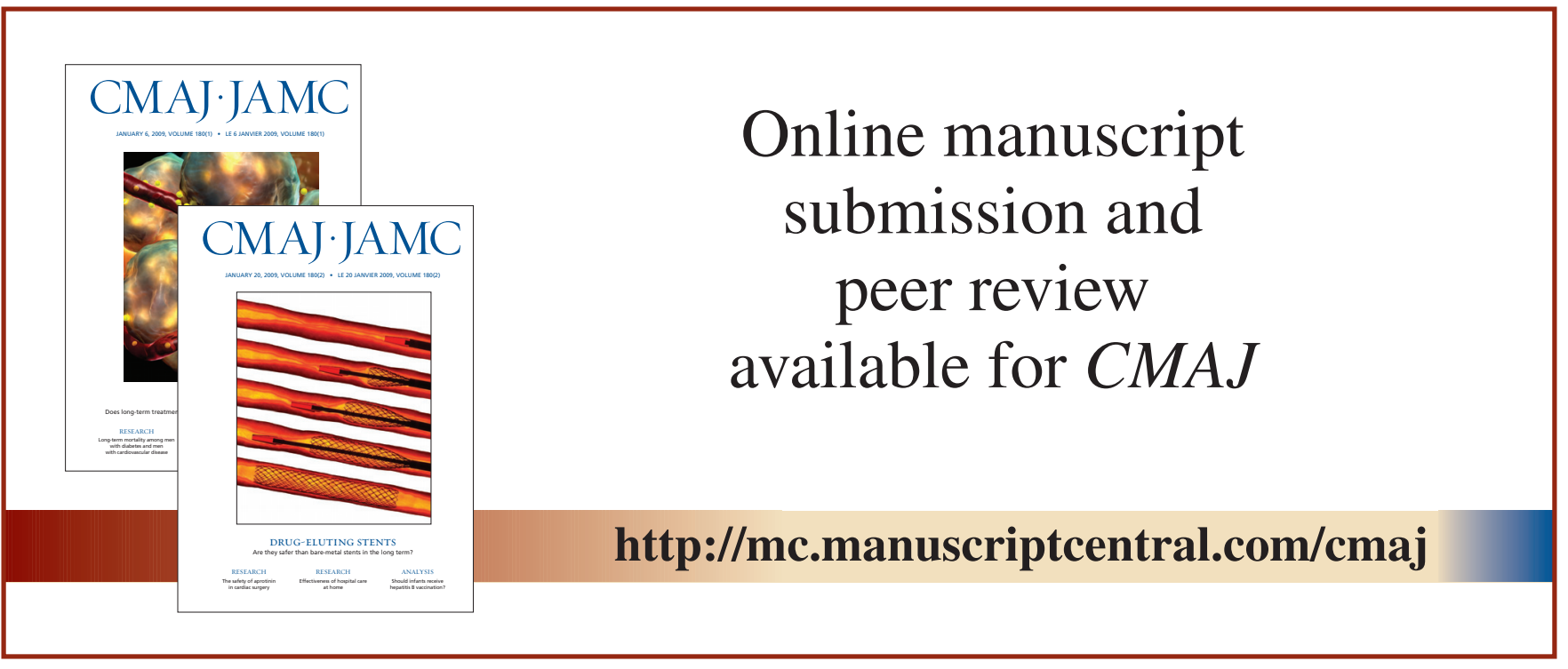

